\title{
Physical Security and Survival of Small and Medium Scale Enterprises (SMEs) in Southeast, Nigeria
}

\author{
Nkechi Cordelia Ojiagu ${ }^{1}$, Hope Ngozi Nzewi ${ }^{2}$ \\ ${ }^{1}$ Department of Cooperative Economics and Management, Awka, Nigeria \\ ${ }^{2}$ Department of Business Administration, Nnamdi Azikiwe University, Awka, Nigeria \\ Email: nc.ojiagu@unizik.edu.ng,hn.nzewi@unizik.edu.ng
}

\begin{abstract}
How to cite this paper: Ojiagu, N.C. and Nzewi, H.N. (2019) Physical Security and Survival of Small and Medium Scale Enterprises (SMEs) in Southeast, Nigeria. American Journal of Industrial and Business Management, 9, 1284-1300.

https://doi.org/10.4236/ajibm.2019.95085
\end{abstract}

Received: March 13, 2019

Accepted: May 28, 2019

Published: May 31, 2019

Copyright $\odot 2019$ by author(s) and Scientific Research Publishing Inc. This work is licensed under the Creative Commons Attribution International License (CC BY 4.0).

http://creativecommons.org/licenses/by/4.0/

\begin{abstract}
The study explored the relationship between physical security and survival of small and medium scale enterprises (SMEs) in Southeast, Nigeria. The objectives of the study are to determine the nature of relationships that exist between fire outbreak and entrepreneurial vision, burglary attacks and delivery-time of products by SMEs in Southeast, Nigeria. Correlation survey research design was employed in the study. Pearson product moment correlation coefficient was used to test the formulated hypotheses at $5 \%$ (percent) level of significance. Findings revealed that there were negative significant relationships that exist between fire outbreaks and entrepreneurial visions of $S M E s^{\prime}$ owners, burglary attacks and delivery-time of products to customers by $S M E s$ in the region. In addition, the constructs were significant at $0.05 \mathrm{lev}-$ el (2-tailed). It is recommended that owners of businesses should ensure commitment to fire safety by putting necessary resources for fire control (suppression agents and personnel training) and procedures (compliance with fire disaster preparedness bylaws). Further, business owners need to provide multiple layers of security (defense in depth) around business areas. We therefore advocate that for business continuity in the region, rapid response to fire outbreaks, burglary attacks and comprehensive preventive strategies are vital.
\end{abstract}

\section{Keywords}

Physical Security, Survival, Small and Medium Scale Enterprises (SMES), Southeast

\section{Introduction}

In a world of perceived uncertainty and danger, the desire for security becomes a 
central concern of political thought and action (Boemcken andSchetter, 2016) [1]. Being secure is one of the most widely acknowledged components of a good life, implying that security is usually thought to be encountered in the absence of threats to certain objects. Fischer and Green (2004) [2] assert that security suggests a stable, relatively predictable environment in which an individual or group may pursue its ends without fear of disturbance or injury. Baldwine (1997) [3] views security as a low probability of damage to acquire values, thus has strong parallels with defense as they both provide protection (Brooks, 2010) [4]. Nevertheless, security may present different meanings to different people given the time, place and context.

Security can be described as stability and continuity of livelihood (stable and steady income); predictability of daily life (knowing what to expect); protection from crime (feeling safe); and freedom from psychological harm (safety from emotional stress which results from the assurances or knowing that one is wanted, accepted, loved and protected in one's community or neighbourhood and by people around (Achumba, IghomerehoandAkporRobaro, 2013 [5]). Drawing inference from the economic aspect of the definition (stable and steady income), which most times is derived from business environment, it does appear that business security is the next crucial discourse apart from human security which is assuring priority freedoms so that people can exercise choices safely and freely (UNDP, 2013) [6]. Business security generally involves physical security (PS), which is the protection of personnel, hardware, software, networks and data from physical actions and events that could cause serious loss or damage to an enterprise, agency or institution. These include protection from fire, flood, natural disasters, burglary, theft, vandalization and terrorism (Rouse, 2015) [7]. The physical insecurity in Southeast Nigeria has increased in recent time and unchecked despite the regional government budget on security, at various levels. Due to their physical insecurity, survival of Small and Medium Scale Enterprises (SMEs) in the region is highly affected. The people were formerly known for their resourcefulness and entrepreneurial spirit.

There is no generally accepted definition of small scale business, because the classification of businesses into either large scale or small scale is a subjective and qualitative judgment. In some countries (United States of America, Japan, Britain and Canada), definitions are given based on turnover; paid employees; type of industry and paid-up capital. However in Nigeria there are versions of definition of small scale business given by CBN; National Economic Reconstruction fund (NER FUND); Companies and Allied matters Decree (AMP, 1990) [8].

In this study Small and Medium Scale Enterprise (SMEs) are enterprises with a maximum asset base of N200 million excluding land and working capital and with the number of employees not less than 10 or more than 100 (SMEIS, 2003) [9]. The definition notwithstanding, SMEs are generally distinguished by the nature of their production and management arrangement, trading relations, financial practice and internal competence. 
Small and Medium Scale Enterprises are essential factors for national objective in terms of employment, development of entrepreneurial capability and indigenous technology. SMEs also minimize the migration of people from rural to urban areas. They also contribute to the country's gross domestic product and development of enduring industrialization. The SMEs are important factors in most economies especially in developing countries (Recklies, 2001) [10]. SMES are quasi spouse for urban employment and providers of inexpensive consumer goods with little or no import content, serving an important pressure releasing and welfare-augmenting function (Ekpeyong and Nyong, 1992) [11]. Considering the proven economic and social benefit of $S M E s$ to Nigeria and Southeast in particular, Aremu (2004) [12], suggests that every organization should see survival (longevity and profitability growth) as absolute prerequisites for serving any interest. Therefore, there appears to be correlation between the degree of physical security and survival of SMEs in an economy.

Despite the potential role and opportunities of SMEs to rebound and play the crucial role of engine of growth in Southeast, Nigeria, empirical evidence has shown that the life span of SMEs tend to be short with approximately two thirds of all start-ups failing within the first five years and of every 100 start-ups only 50 firms survive the first three years (Ladzani and Van Vuuren, 2002 [13], Van Praag, 2003) [14]. The closure of SMEs are sometimes occasioned by inadequate infrastructural facilities; inconsistent monetary, fiscal and industrial policies; limited access to markets; multiple taxation and levies, lack of modern technology for processing and preserving products, policy reversals; capacity limitations; data inadequacies, harsh operating environment; fragile ownership base, fragile capital base but majorly insecurity of lives and prosperity (Nwoguand Onugu, 2005) [15]. The last sentence on insecurity connotes that physical security is critical to $S M E s$ survival. Physical security includes protection from fire; flood; natural disasters, burglary, theft, vandalism and terrorism. Due to overlook on physical security, survival of SMEs in the study area is seriously challenged and may cause loss of entrepreneurial vision; real delivery time of goods and services to customers. Moreover, each year people die or are seriously injured and properties destroyed as a result of fire outbreaks at work. Besides lost of lives, fire costs millions of Naira damage to property; loss of business, fire compensation and insurance premium Statistics. Burglary at business premises has increased in wave leading to loss of merchandise, the anticipated profit and possible loss of customers.

A disconnect however exists between the influences of fire out breaks and burglary attacks on entrepreneurial vision of businesses and customers delivery time of goods and services as constructs of physical security and survival of SMEs (non-financial indicator) respectively. This therefore has led to undertaking a study to assess the relationship between physical security and survival of $S M E s$ in Southeast, Nigeria.

In view of this, the primary objective of the study is to explore the relationship between physical security (PS) and survival of Small and Medium Scale Enter- 
prise (SMEs) in Southeast, Nigeria. Specifically, the study seeks to:

1) Determine the nature of relationships that exist between fire out break and entrepreneurial vision of Small and Medium Scale Enterprise (SMES) in southeast, Nigeria.

2) Ascertain the nature of relationships that exist between burglary attacks and delivery-time of products by Small and Medium Scale Enterprise (SMEs) in South East, Nigeria.

Consequently, the direction hypotheses are that:

$\mathrm{H}_{1}$ : There is a significant relationship that exists between fire outbreak and entrepreneurial vision of Small and Medium Scale Enterprise (SMES) in Southeast, Nigeria.

$\mathrm{H}_{2}$ : There is a significant relationship that exists between burglary attacks and delivery-time of products by Small and Medium Scale Enterprise (SMEs) in Southeast, Nigeria.

\section{Conceptual and Theoretical Issues}

\section{Physical Security}

Physical security describes measures designed to ensure the physical protection of facilities, equipment; personnel; resources and other properties from damage and unauthorized physical access. Physical security measures are taken in order to protect organization assets from physical threats including theft, vandalism, fire, terrorism and natural disasters (Cobb, 2009) [16]. Physical security is often the first concern in facilities with high assets concentration that are used incritical systems for business processes. Physical security is especially important for all organization resources, as their proper operation demands that assets and infrastructure they are running on be kept away from anything that could hinder their function. This includes tampering by unauthorized personnel and unforeseen events like accidents, fire, burglary and natural disasters. Bennett (2017) [17] asserts that physical security doesn't just increase safety, it increases the legitimacy of businesses, hence deterrence and detection of physical security becomes second nature of organizations. Deterrences are methods and measures that are meant to defer attackers and intruders or prevent natural events and accidents from affecting protected assets. The simple method for this is through the use of physical barriers and signs. The signs serve as a warning to any intruder that their actions will bring physical harm or prosecution. The barriers are meant to prevent access entirely or simple to provide protection from external factors like storms or fire accidents. Detection allows security personnel to detect and locate potential intruders using surveillance equipment like cameras, motion sensors, security lights and personnel like security guards and watch dogs (Techopedia, 2018). Cobb (2009) opines that physical security has three important components which are: access control, surveillance and testing.

\section{Fire Outbreak}

Fire is the rapid oxidation of a material in the exothermic chemical process of 
combustion, releasing heat, light and various reaction products (Wikipedia, 2018). Fire outbreak connotes sudden increase in occurrences of fire in a particular time and place. Dynes and Russell (2002) [18] opine that there is fast growth in urban places of all sizes from small markets to mega-cities; this increased development interactions increase the risk of fire occurrences as well. Fires have occurred in almost all commercial cities in Nigeria, more recently is the Eco Bank Headquarter Inferno at Lagos. In Southeast, Nigeria, fire disasters have not affected only markets, private household offices but strategic businesses and installations. Lives have been lost due to the fires and damage to property worth billions of naira has been experienced. According to Lagos State Government (2017), no fewer than 84 persons were burnt to death and property worth N128 million destroyed in the state. A total of 333 victims were rescued during the fire incidents. There were fire outbreaks at Enugu Timber market destroying goods worth millions (March 5, 2018) and disaster at Bridge Head Market in (December, 20, 2017). On March 7, 2018 there was a disaster at Aba, Main Market. Stories were not told of Oil Tankers' futures and consequent fires on business premises. Nuhu (2018) [19] asserts that fire best fighting technique is prevention and the best strategy for recovery is insurance, the ideas stem from whenever fire disaster occurs in a business premises attention and resources are diverted, destroying entrepreneurial vision (orientation), drive and leadership in already competitive business environment (Victoria, 2011) [20].

\section{Burglary Attack}

Burglary is the felonious forceful breaking and entering of an enclosure such as building or a receptacle such as a chest, safe, or vault for the purpose of committing a felony such as stealing valuable property (Girard, 1960) [21]. Girard further states that merchandise is business, without it there can be no business and protection of property is of vital importance; the act of burglary result in loss of valuable property which is as old as man. As long as man has been, the urge to acquire the property of another has existed. The hazards to which valuable property is subjected today are no different than in the days of early history except that the frequency of occurrence is greater today. Girard, continuing, asserts that the very numerous losses of property costs owners a huge annual sum. It seems reasonable that adequate protection will save much property which is needlessly lost. The value of property saved by adequate protective measures will far exceed the cost of good protection. Protection of property costs money, and it is a major item in the cost of operation of business. It can be the factor that determines success, survival or failure in business, for burgled business premises undermined delivery dependability to customers thus gives credence to customer's dissatisfaction. On time delivery elucidates ability of the customers getting what they want, when they want it; agreement on units ordered and date of delivery.

\section{Survival of Business}

Survival is related to business success is a long term financial sustainability of 
a business over indefinite period. For a emerging economy like Nigeria, survival of $S M E s$ is of importance since they contribute greatly to the economic development, job creation and GDP. Survival in this study is decomposed to longevity and non financial indicators of entrepreneurial vision (entrepreneurial orientation) and delivery-time (delivery dependability). Most managers pursue strategies that enable their organizations to continue in operation for a long term (Broom, 2003). Survival is closely linked to a new product development, profit; sales, market share and image; the longer one can survive and prevent involuntary exist the more successful the business becomes (VarNich, 2012 [22] Lanpraag, 2003) [23]. Survival therefore is a continued existence in business over a protracted period of time as well as the ability of a business. Amahand Okoisama (2017) [24] argue that survival of SMEs can be described as the firm's ability to create acceptable outcomes and actions. It is also evident that small firm survival is the firm's success in the market, which may have different outcomes (Emmanuel; 2013 [25], Awolusi andIbojo, 2013) [26].

\section{Longevity}

Longevity is defined as having continuity in business for a long period of time (Gorglevski, 2011) [27]. Longevity is related to the survival and continuity of an enterprise and is one of the measures of firms success other than profit, growth innovation, social and environmental performance. Williams and Jones (2009) [28] describe longevity as the duration (age) of the business, that is time elapsed since the firm started operation. Business longevity is associated with a firm's lifecycle. For a business to be existence for a long time, it must have passed through the initial stages of the firms' life cycle. The longer a business can survive and prevent involuntary exist the more successful one is (Van, Praag, 2003). Business longevity can be used synonymously with business survival. In order for a business to remain solvent, it has to sustain itself, indicating that longevity is a measure of success (Lubinski, Fernandez and Moya, 2011) [29].

\section{Small Scale Businesses}

The term Small and Medium Scale Enterprise (SMES) are relative and differ from industry to industry, country to country and there is no universally accepted definition of $S M E s$. There is no single criterion for classifying a business enterprise as small and medium scale. Definition changes overtime and importantly depends upon a country's level of development (Nwogu andOnugu, 2005).

In Nigeria, the multiplicity of definitions for small and medium scale enterprises is the role rather than expectation. It is however possible that as a result of difference in policy focus, different government agencies in Nigeria applies various definitions on SMEs (Nwankwo, Ewuim andAsoanya, 2012) [30]. The Central Bank of Nigeria (CBN) in its 1990 credit guideline for financial institution define SMEs as those businesses whose annual turnover does not exceed N200,000,000 or capital expenditure does not exceed N200,000,000. National Council of Industries refer to $S M E s$ as enterprises whose total costs excluding land is not more than N200000000.00 only. While SMEIS (2003) see SMEs as 
any enterprise with a maximum asset base of N200 million excluding land and working capital and with the number of employees not less than 10 or more than 300.

Typically, the following features in varying degree characterized SMEs in Nigeria. Small units, often rural based and family owned, small independent-enterprise standing along and producing for a well define market, specialized firm, producing special product; selling to international and local market, rely on low raw materials; low energy cost, low labour cost, low division of labour; flexibility and often small production turns; low capital formation and largely labour intensive units with low level technologies. SMEs encompass sole proprietorship, family business and partnership and may be incorporated. Moreso, the term includes such professionals and architectures that are self-employed (Gollin, 2008) [31].

\section{Entrepreneurial Vision (Entrepreneurial Orientation)}

This concept is also seen as entrepreneurial orientation, covering to be essentials for firms; growth (Soininen, Martikainen, Puumalainen andKylaheiko, 2011) [32]. Profitability (Antonicnu, 2007) [33] and overall performance (Al-Swidi and Mahmood, 2011) [34] and have positive effect on growth of small and medium enterprises (Gurbuz and Aykol, 2009) [35]. Entrepreneur Orientation (EO) is seen as decision making with regards to the firms strategy to embarkon innovation, proactiveness and risk taking (Ambad and Wahab, 2013) [36]. It is also seen as methods, drive practices and decision making styles of entrepreneurial managers on how a firm intends to complete in today's business environments, where firms device means and leadership to survive. Being entrepreneurial oriented means being alert to challenges that business environment poses and continually evolving strategies to surmount those challenges (Zainol andDavd, 2012) [37]. These challenges could be in form of fire outbreaks and burglary (Jebna andBaharudin, 2015) [38]. Entrepreneurial and vandalism orientation constructs include; innovativeness, proactiveness, risk-taking, competitive aggressiveness and autonomy (Al-Swidi and Al-Hosam, 2012, Hughes and Morgan, 2017) [39].

\section{Delivery-Time (Dependability)}

Delivery-Time is interchanged in this study as Delivery-Dependability. Nair and Pandey (2005) [40] define delivery dependability as the ability to meet quoted or anticipated delivery dates and quantities on a consistent basis. Delivery dependability is the ability of an organization to provide on time the type and volume of product required by customers(s).

Delivery is a competitive priority because customers are interested in satisfying their needs and wants in the right quantity at the right time. Kumar and Kuma (2004) [41] state that delivery of the required function means ensuring that the right product (meeting the requirements of quality, reliability and maintainability) is delivered in the right quantity, at the right time, in the right place, from the right source (a vendor who is reliable and will meet commit- 
ments in a timely fashion), with the right service (both before and after sale), and finally, at the right price. Audretsch (2003) [42] argues that delivery capability is a time issue where if reflects the following concepts: the number of aspects of a firm's operations, how quickly a product or service is delivered to a customer, how reliably the products or services are developed and brought to the market, and the rate at which improvements in products and processes are made. Delivery capability is of great importance due to the current global nature of business and the shift-towards Just-In-Time (JIT) practices by organizations (Koufteros, Vonderembse and Doll, 2002) [43].

\subsection{Theoretical Framework}

The study is anchored on the social disorganization theory by (John Hagan, 1960). The theory seeks to explain comment differences in crime rates, why some individuals are more likely to engage in crime than others. Crime is said to be more likely in communities that are economically deprived, large in size, high in multiunit housing, high in residential mobility (people frequently move into and out of the community) and high in family disruption. These factors are said to reduce the ability or willingness of community residents to exercise effective social control. The theory has relevance to this work in that resident's of high crime areas often lack the skills and resources to effectively assist others. They are poor struggling with responsibilities and with limited resources thereby sometimes engage in crime as a result. They may engage in burglary activities to reduce or escape from the strain they are experiencing.

\subsection{Empirical Review}

Achumba, Ighomereho and Akpor-Robaro (2013) evaluated security challenges in Nigeria and implications for Business Activities and Sustainable Development. Secondary data and observations were adopted to elicit information from different zones of the country. Findings of the study show that safe business environment allows for effective business activities and a sustainable development process.

Ayodele (2015) studied Crime-Reporting Practices Among Market Women in Oyo, Nigeria. The study adopted quantitative and qualitiative approaches. Copies of questionnaire were administered to collect quantitative data from randomly selected 210 market women. Five focus group discussions, in-depth and key informant interviews were conducted to complement quantitative data. The study found that cultural considerations stand between crime events that hurt the economic interests of women and their readiness to report to the police. It therefore suggests that the government should address public safety to enable market women make their modest contribution to Nigeria's economic development.

Hutter (2016) evaluated physical security and why it is important. The study adopted a conceptual approach and found that physical security has technical 
and administrative elements which are often overlooked because most organizations focus on technology-orientated security countermeasure to prevent hacking attacks. Moreover, physical security objective is to safeguard personnel, information, equipment, IT infrastructure, facilities and all other company assets further, the strategies used to protect the organization's assets need to have a layered approach.

Ibidunni, Iyiola and Ibidunni (2014) studied product innovation, a survival strategy for small and medium enterprises in Nigeria. The objective of the study was to determine the relationship between product innovation and the survival of small and medium enterprises in Nigeria. A survey research approach was adopted and 217 copies of questionnaire were administered to 217 respondents. Data generated were analyzed using Spearman correlation and Z-test. Finding showed a significant relationship between product innovation and survival of SMEs.

Ashish, Vikas and Shahnawaz (2009), Investigated linking information sharing and supplier network responsiveness with delivery dependability of a firm in USA. Questionnaire was used for data collection. Data were analyzed using Pearson Product Moment Correction. The research findings revealed that higher level of information sharing practices can lead to improved supplier network responsiveness and higher level of supplier network responsiveness can have a direct positive impact on delivery dependability of a firm.

\section{Summary of Review of Related Literature}

Literature in this area appears not much, however, some studies examined security challenges in some parts of Nigeria. However, none of the studies was carried out in Southeast, Nigeria.

Studies have shown that prevention of crime against small businesses can effectively reduce the vulnerability of individual businesses, however, none on physical security and survival of SMES.

In an effort to extend the knowledge frontier, this study therefore compliments previous research in closing the literature gap, by exploring the nexus between physical security and survival of $S M E s$ in Southeast, Nigeria.

\section{Methods}

\section{Research Design}

The study adopted correlation survey research design in order to elicit data from a large number of respondents with various characteristics and to ascertain the nature of relationships existing among the variables. Data for the study were collected using questionnaire instrument.

\section{Population of the Study}

The population of the study comprises of $S M E s$ in South-East Nigeria. The distribution of the population is given below thus:

Table 1 shows the distribution of SMEs among the five states in South East Nigeria. The accumulated population figure is six thousand five hundred and thirteen (6513). 
Table 1. Population distribution.

\begin{tabular}{lll}
\hline$S / N$ & States & Population \\
\hline 1. & Abia & 3435 \\
2. & Anambra & 1137 \\
3. & Ebonyi & 1001 \\
4. & Enugu & 776 \\
5. & Imo & 164 \\
& Total & 6513 \\
\hline
\end{tabular}

Source: http://www.businesslist.com.ng. Nigeria Business Directory.

\section{Sample Size and Sampling Technique}

The sample size of the study was determined using Krejcie and Morgan (1970) formula for sampling from definite population. The formula is shown below.

$$
s=\frac{x^{2} N P(1-P)}{d^{2}(N-1)+x^{2} P(1-P)}
$$

where:

$s=$ Sample size;

$x^{2}=$ Table value of chi-square for 1 degree of freedom at $0.05 \%$ confidence level (3.84);

$N=$ Population size (6513);

$P=$ Population proportion (assumed to be 0.5 as this would provide the maximum sample size);

$d=$ Degree of accuracy expressed as a proportion (0.05).

$$
\begin{gathered}
s=\frac{3.84(6513)(0.5)(1-0.5)}{(0.05)^{2}(6513-1)+(3.84)(0.5)(1-0.5)} \\
S=\frac{6252.48}{16.28+0.96} \\
s=\frac{6252.48}{17.24} \\
s=362.67 \\
s \cong 363
\end{gathered}
$$

To distribute questionnaire in proportion to the population of $S M E s$ in each of the five states, Bowley's allocation formula was utilized. The Bowley's formula is given below:

$$
n h=\frac{n N h}{N}
$$

where:

$n=$ Total sample size;

$N h=$ Number of items in each stratum in the population;

$N=$ Population size;

Abia $363 \times 3435 / 6513=192$;

Anambra $363 \times 1137 / 6513=63$; 
Ebonyi $363 \times 1001 / 6513=56$;

Enugu $363 \times 776 / 6513=43$;

Imo $363 \times 164 / 6513=9$.

\section{Instrument for Data Collection}

Structured questionnaire was employed for data collection. The questionnaire was structured following Likert scaled format. The scales are as follows: Strongly Agree (5), Agree (4), Disagree (3), Strongly Disagree (2) and Undecided (1). The instrument was divided into six (6) sections with a total of thirty six (36) questionnaire items.

\section{Validity of Instrument}

The instrument was validated using panel of experts in management, security and fire services. This was to ensure that the questionnaire instrument provided adequate coverage for the variable of the study and to also ensure that the items are simple, unambiguous and precise (Azuka, 2011) [44].

\section{Reliability of the Instrument}

Using Cronbach Alpa technique, the instrument was checked for internal consistency. A coefficient of 0.893 was obtained as shown in Table 2.

\section{Method of Data Analysis}

Pearson's Product Moment Correlation Coefficient (PPMCC) was adopted in analysis the data given that the intent of the study was to determine the relationship existing between the variables of the study.

\section{Decision Rule}

The study used 5\% (0.05) level of significance signifying a 95\% level of confidence. This guided the interpretation of result for hypothesis testing.

\section{Data Presentation and Analysis}

\section{Data Presentation}

Table 3 shows the questionnaire distribution schedule. From the table, it reveals that a total of three hundred and sixty three (363) copies of questionnaire were distributed representing $100 \%$ of the sample size, three hundred and twenty four (324) representing $89 \%$ of the distributed copies were collected and three hundred and seventeen (317) copies representing $87 \%$ of the distributed copies were finally analyzed while thirty nine copies (39) representing $11 \%$ got missing.

Table 4 shows the biographic details of the respondents. From the table, it shows that $49 \%$ of the respondents engage in sale/distribution of goods, $40 \%$ are involved in production while $11 \%$ provide services. The table indicates that 125 of the respondents are male while 192 are female meaning that more females participated in the survey than male. It reveals that there are more businesses that have operated between 1 - 5 years with $46 \%$. 15\% of the businesses have been in operation between 6 - 10 years, 24\% have existed between 11 - 15 years, $10 \%$ have operated between 16 - 20 years while $5 \%$ have been in operation for 21 years and above. A greater percentage of the businesses operate in the urban area with $49 \%, 33 \%$ operate in semi-urban areas while $8 \%$ operate in rural areas. 
Table 2. Reliability statistic.

\begin{tabular}{cc}
\hline Cronbach's Alpha & Nof Items \\
\hline 0.893 & 20 \\
\hline
\end{tabular}

Source: Field Survey, 2018. Computation: SPSS Ver. 20.

Table 3. Questionnaire distribution schedule.

\begin{tabular}{cccccc}
\hline $\boldsymbol{S} / \boldsymbol{N}$ & States/Organizations & Distributed & Collected & Lost & Analyzed \\
\hline $\mathbf{1}$ & Abia & 192 & 165 & 27 & 161 \\
$\mathbf{2}$ & Anambra & 63 & 61 & 2 & 61 \\
$\mathbf{3}$ & Ebonyi & 56 & 50 & 6 & 48 \\
$\mathbf{4}$ & Enugu & 43 & 39 & 4 & 38 \\
$\mathbf{5}$ & Imo & 9 & 9 & 0 & 9 \\
& Total & $363(100 \%)$ & $324(89 \%)$ & $39(11 \%)$ & $317(87 \%)$ \\
\hline
\end{tabular}

Source: Field Survey, 2018.

Table 4. Demographic factors.

\begin{tabular}{|c|c|c|c|c|c|c|}
\hline$N$ & Biography & & Options & & & \\
\hline \multirow[t]{3}{*}{1} & Business Type & $\mathrm{S}$ ales/Distribution & Production & \multicolumn{3}{|c|}{ Services } \\
\hline & Frequency & 154 & 128 & \multicolumn{2}{|c|}{35} & \\
\hline & Percentage & $49 \%$ & $40 \%$ & \multicolumn{2}{|c|}{$11 \%$} & \\
\hline \multirow[t]{3}{*}{2} & Gender & Male & Female & & & \\
\hline & Frequency & 125 & 192 & & & \\
\hline & Percentage & $39 \%$ & $61 \%$ & & & \\
\hline \multirow[t]{3}{*}{3} & $\begin{array}{c}\text { Years of Business } \\
\text { Experience }\end{array}$ & $1-5$ & $6-10$ & $11-15$ & $16-20$ & $\begin{array}{l}21 \text { and } \\
\text { above }\end{array}$ \\
\hline & Frequency & 147 & 48 & 75 & 30 & 17 \\
\hline & Percentage & $46 \%$ & $15 \%$ & $24 \%$ & $10 \%$ & $5 \%$ \\
\hline \multirow[t]{3}{*}{4} & Business Location & Rural & Semi-Urban & \multicolumn{2}{|c|}{ Urban } & \\
\hline & Frequency & 56 & 104 & \multicolumn{2}{|c|}{157} & \\
\hline & Percentage & $18 \%$ & $33 \%$ & \multicolumn{2}{|c|}{$49 \%$} & \\
\hline
\end{tabular}

Source: Field Survey, 2018.

\section{Test of Hypothesis}

$\mathbf{h}_{\mathrm{ai}}$ : There is a significant relationship existing between fire outbreak and entrepreneurial vision of $S M E s$ in Southeast, Nigeria.

Table 5 shows the details of correlation analysis carried out to determine the nature of relationship that exists between fire outbreak and entrepreneurial vision of SMEs in Southeast, Nigeria. The result indicates that there is a statistically significant negative relationship between the variables. This is occasioned by the fact that the correlation coefficient obtained was negative $(-0.801)$ and the $\mathrm{p}$-value is 0.000 which is less than, 05 ( $\mathrm{p}$-value $<05$ ). Hence, the research hypo- 
thesis is accepted.

$\mathrm{H}_{\mathrm{Ai}}$ : There is a significant relationship existing between burglary attacks and delivery-time of products by SMEs in Southeast, Nigeria.

Table 6 reveals the result of the correlation analysis carried out to ascertain the nature of relationship that exists between burglary attacks and delivery-time of products by SMEs in Southeast, Nigeria. From the result, it shows that a statistically significant (negative) relationship exists between the variables since the Pearson's $r$ is negative $(-751)$ while the p-value is 0.000 which is lesser than 0.05 level of significance.

\section{Discussion of Findings}

The discussion is done according to the research objectives as follows:

The first objective relates fire outbreak with entrepreneurial visions of SMEs in south east, Nigeria. Analysis shows that it is statistically significant judging by the result $(r=-0.801, p>0.000)$, however, the direction of relationship is negative. The implication of the findings questions the potency of entrepreneurial visions of SMEs owners in the region occasioned by fire outbreaks. The findings are consistent with Achumba, Ighomereho and Akpor-Robaro (2013) where safe business environment allows for effective business activities and a sustainable development process.

Table 5. Correlation Output for fire outbreak and entrepreneurial vision, Correlations.

\begin{tabular}{|c|c|c|c|}
\hline & & FIREOUT & ENTREVISI \\
\hline \multirow{3}{*}{ FIREOUT } & Pearson Correlation & 1 & $-0.801^{\prime \prime}$ \\
\hline & Sig. (2-tailed) & & 0.000 \\
\hline & $N$ & 317 & 317 \\
\hline \multirow{3}{*}{ ENTREV1SI } & Pearson Correlation & $-0.801^{\star \star}$ & 1 \\
\hline & Sig. (2-tailed) & 0.000 & \\
\hline & $N$ & 317 & 317 \\
\hline
\end{tabular}

${ }^{* *}$ Correlation is significant at the 0.01 level (2-tailed). Source: Field Survey, 2018. Keys: FIREOUT: Fire Outbreak, ENTREVISI: Entrepreneurial Vision.

Table 6. Correlation Output for burglary attacks and delivery-time, Correlations.

\begin{tabular}{cccc}
\hline & & BURGATT & DTI ME \\
\hline \multirow{2}{*}{ MEETTINGS } & Pearson Correlation & 1 & $-0.751^{\prime \prime}$ \\
& Sig. (2-tailed) & & 0.000 \\
& $N$ & 317 & 317 \\
SURVIVAL & Pearson Correlation & $-0.751^{\prime \prime}$ & 1 \\
& Sig. (2-tailed) & 0.000 & 317 \\
\hline
\end{tabular}

${ }^{* *}$ Correlation is significant at the 0.01 level (2-tailed). Source: Field Survey, 2018. Keys: BURGATT: Burglary Attacks, DTIME: Delivery Time. 
The second objective explored the relationship between burglary attacks and delivery-time of products by SMEs Result shows that a statistically significant (negative) relationship exists between the variables by $(\mathrm{r}=-0.751, \mathrm{p}>0.000)$ implying that the more the burglary attacks, the more the loss of delivery dependability by SMEs. The result supports the work of Koufteros, Vonderembse and Doll (2002) that an organization without Just-In-Time (JIT) practices has lost competitive priority.

Additional implication of the findings on the study objectives indicates that the clustered opinions of respondents on the ordinal scale measurement have brought to fire the real situation of many SMEs on physical security and business survival, in southeast, Nigeria.

\section{Conclusion}

Based on the results of the study, it is evident that there are negative significant relationships between fire outbreaks and entrepreneurial visions of the SMES owners and burglary attacks and delivery-time of products, to customers by the $S M E s$ in the region. In addition, despite the negative relationship, the four constructs are significant at 0.000 (2-tailed) level of significance.

\section{Recommendations}

Emanating from the outcome of the study, the following recommendations are made:

1) Owners of business need to ensure commitment to fire safety in the business premises by putting necessary resources in place to guard against fire disaster.

2) The fire service units in the states of Southeast, Nigeria need to improve on enforcing law as regards fire safety in business areas to ensure that set rules and standards are maintained.

3) Business owners need to provide security gates and shutters within the premises. Folding security gates and roll-down shutters inside windows and doors provide additional security. Moreover, all critical spaces, ventilation windows and other openings need to be secured in order to prevent access through them.

4) Apart from government police outfit, owners of business need to arrange for private security services to boost further safety.

\section{Conflicts of Interest}

The authors declare no conflicts of interest regarding the publication of this paper.

\section{References}

[1] Achumba, I.C., Ighomereho, O.S. and Akpor-Robaro, O.M. (2013) Security Challenges in Nigeria and Implications for Business Activities and Sustainable Devel- 
opment. Journal of Economics and Sustainable Development, 4, No. 2.

[2] Amah, E. and Okoisama, T. (2017) Risk Raking and Survival of Small and Medium Scale Enterprises in Nigeria. Archives of Business Research, 5, No. 11. https://doi.org/10.14738/abr.511.3769

[3] Antoncic, B. (2007) Intrapreneurship: A Comparative Structural Equation Modeling Study. Industrial Management and Data Systems, 107, 309-325. https://doi.org/10.1108/02635570710734244

[4] Al-Swidi, A.K. and Al-Hosam, A. (2012) The Effect of Entrepreneurial Orientation on the Organizational Performance: A Study on the Islamic Banks in Yemen Using the Partial Least Squares Approach. Arabian Journal of Business and Management Review, 2, 73-84. https://doi.org/10.12816/0002244

[5] Al-Swidi, A.K. and Mahmood, R. (2011) Enhancing a Bank's Competitive Advantage through the Integration of TQM Practices, Entrepreneurial Orientation (EO) and Organization Culture. European Journal of Social Sciences, 20, 299-313.

[6] Ashish, A.T., Vikas, A. and Shashawaz, I. (2009) Linking Information Sharing and Supplier Network Responsiveness with Delivery Dependability of a Farm. The Journal of Applies Business Research, 25, No. 3.

[7] Audretsh, D.B. (2003) Entrepreneurship: A Survey of the Literature. Enterprise Paper No. 14. Enterprise Directorate-General European Commissions.

[8] Ayodele, J.O. (2015) Crime-Reporting Practices among Market Women in Oyo, Nigeria. SAGE Open, 5, 1-11. https://doi.org/10.1177/2158244015579940

[9] Azuka, E.B.C. (2011) Research Methods: Theory and Applications. Noben Publishers, Nigeria.

[10] Beemcken, M.V. and Schetter, C. (2016) Reflection Group Monopoly on the Use of Force 2. O. Friedrich Ebert Stiftung, Germany.

[11] Beneff, A. (2017) Why Physical Security for Your Business Is Just as Critical as Online Security. https://www.entrepreneur.com

[12] Broojs, D.J. (2010) What Is Security: Definition through Knowledge Categorization. Security Journal, 23, 225-239.

[13] Broom, L. (2003) Small Business Management. Western Publishing Inc., Cincinnati, $\mathrm{OH}$.

[14] Cobb, M. (2009) Physical Security Threats: Don’t Gift Your Data Away.

[15] Dynes, R. and Russel, N. (2012) A Prospective on Disaster Planning. Disaster Research Centre, Newark, DE.

[16] Ekpenyong, D.B. and Nyong, M.O. (1992) Small and Medium-Scale Enterprises in Nigeria. Their Characteristics, Problems and Sources of Finance. African Economic Research Consortium, Nairobi.

[17] Emmanuel, A.T., Awolusi, O.D. and Ibojo, B.O. (2013) Determinants of Small and Medium Enterprises (SMEs) Performance in Ekiti State. Nigeria: A Business Survey Approach. European Journals of Humanities and Social Sciences, 27, 1397-1413.

[18] Ernst and Young (2012) Enterprise Security Architecture Business Driven Security.

[19] Fisher, R.J. and Green, G. (2004) Introduction to Security. Butter Worth-Heinemann, Boston, MA.

[20] Galadanchi, H.A. and Bakar, L.J. (2018) A Study of Factors that Support Longevity of Business Enterprises. Journal of Business and Management, 20, 53-59.

[21] Girard, P.J. (1960) Burglary Trends and Protection. Journal of Criminal Law and Criminology, 50, 511-518. https://doi.org/10.2307/1141029 
[22] Gollin, D. (2008) Nobody's Business but My Own: Self-Employment and Small Scale Enterprise in Economic Development. Journal of Monetary Economics, 55, 219-233. https://doi.org/10.1016/j.jmoneco.2007.11.003

[23] Gurbuz, B.A. and Aykol, S. (2009) Entrepreneurial Management, Entrepreneurial Orientation and Tur Kish Small Firm Growth. Management Research News, 32, 321-336. https://doi.org/10.1108/01409170910944281

[24] Hughes, M. and Morgan, R.E. (2007) Deconstruction of the Relationship between Entrepreneurial Orientation and Business Performance at the Embryonic Stage of Firm Growth. Industrial Marketing Management, 36, 651-661. https://doi.org/10.1016/j.indmarman.2006.04.003

[25] Hunter, D. (2016) Physical Security and Why It Is Important. The SANS Institute.

[26] Ibidunni, O.S., Iyiola, O. and Ibudunni, A.S. (2014) Product Innovation a Survival Strategy for Small and Medium Enterprises in Nigeria. European Journal of Business and Management, 5, 179-186.

[27] Jebna, A. and Baharudin, A.S. (2015) The Impact of Entrepreneurial Orientation on Manufacturing SME Performance with the Contingent Effect of e-Commerce in Malaysia. Advances in Environmental Biology, 9, 24-27.

[28] Dileep, M.K. (2012) Entrepreneurial Orientation and Internationalization of SMEs. International Economics \& Finance Journal, 7, 1-27.

[29] Maltiotra, M.K., Saeed, K.A. and Nair, A. (2009) Entrepreneurial Orientation and Firm Performance. An Empirical Examination of Manufacturing Strategy Typology Based on Corporate Entrepreneurship. Unpublished Manuscript.

[30] Nair, K.R.G. and Pandey, A. (2006) Characteristics of Entrepreneurs: An Empirical Analysis. The Journal of Entrepreneurship, 15, 47-61.

https://doi.org/10.1177/097135570501500104

[31] Nuhu, A. (2018) The Imperative for Insurance Cover Against Fire Disaster.

[32] Nwankwo, F., Ewuim, N. and Asoanya, N.P. (2012) Role of Cooperative in Small and Medium Scale Enterprise Development in Nigeria: Challenges and Way Forward. International Multidisciplinary Journal, 6, 140-156.

https://doi.org/10.4314/afrrev.v6i4.10

[33] Nwogu Onugu, B.A. (2005) Small and Medium Enterprises (SMEs) in Nigeria: Problems and Prospects. Dissertation Submitted to the St. Clements University.

[34] Ladzani, W.M. and Van Vuurem, J.J. (2002) Entrepreneurship Training for Emerging SMEs in South-African. Journal of Small Business Management, 40, 154-161. https://doi.org/10.1111/1540-627X.00047

[35] Lubinski, C., Fernandez, P. and Moya, M.F. (2011) Standing the Test of Time. Factors Influencing Family Firms' Longevity in Germany and Spain during Twentieth Century.

http://www.ebha.org/ebha2011/files/papers/standingTestTimeM\%20Fernandez-p\% 20Fernandez-C\%20Lubinsky.Pd

[36] Recklies, D. (2001) Small Business-Size as a Chance or Handicap. Management Project.

[37] Rouse, M. (2015) Relationship Marketing Definition. http://www.Techtarget.com

[38] SMEIS (2003) Prospect of Nigeria SMEs under the Small and Medium Industries Equity Investment Scheme (MELS). http://www.nigerabusiness.info.com

[39] Soninem, J., Martikinen, M., Puumalainen, K. and Kyläheiko, K. (2011) Entrepreneurial Orientation: Growth and Profitability of Finnish Small-and Medium-Sized Enterprises. International Journal of Production Economics, 140, 614-622. 
[40] United Nations Development Programme (UNDP) Human Security: A Thematic Guidance Note for Regional and National Human Development Report. Human Development Report Office.

[41] Vanpraag, C.M. (2003) Business Survival and Success of Young Small Business Owners. Small Business Economics, 21, 1-17.

[42] Victoria, L.W. (2003) Community Based Approaches to Disaster Mitigation. Center for Disaster Preparedness, Philipines.

[43] Winch, G.M. (2014) Three Domains of Project Organising. International Journal of Project Managements, 32, 721-731. https://doi.org/10.1016/j.ijproman.2013.10.012

[44] Zainol, F.A. and Daud, N.D. (2011) Indigenous (Bumiputera) Malay entrepreneurs in Malaysia: Government Supports, Entrepreneurial Orientation and Firms Performance. International Business and Management, 32, 86-89. 